\title{
Acute retinal detachment after Nd:YAG treatment for vitreous floaters and postertior capsule opacification: a case report
}

\author{
Xiuduo Liu*, Qian Wang and Jie Zhao
}

\begin{abstract}
Background: Modern laser surgery uses Nd:YAG laser capsulotomy for posterior capsule opacification (PCO) and Nd: YAG laser vitreolysis for symptomatic vitreous floaters (VF). We report a case of acute retinal detachment seven days after Nd:YAG laser capsulotomy combined with Nd:YAG laser vitreolysis and analyze the cause of this complication.

Case presentation: A 58-year-old myopic woman complained of decreased visual acuity and symptomatic floaters with her left eye for 3 months. We found she had significant PCO and VF in the posterior vitreous. She underwent neodymium-doped yttrium aluminum (Nd:YAG) laser vitreolysis immediately after Nd:YAG capsulotomy. After 7 days, she complained of rapid vision decline and dark shadows in her treated eye. We found she had a acute severe rhegmentogenous retinal detachment (RD) involving the macula. Then she underwent vitrectomy, retinal reattchment and silicone oil tamponade surgery immediately. Six months later, silicone oil was removed and the best corrected visual acuity (BCVA) of her left eye gradually improved to 10/20 and maintained during a 1-year follow-up period.

Conclusion: As myopic patients are at risk of developing retinal detachment, Nd:YAG vitreolysis and capsulotomy should be performed with caution. The laser energy should be as low as possible and careful focus is necessary to reduce interference to the retina.
\end{abstract}

Keywords: Nd:YAG vitreolysis;vitreous floaters, Capsulotomy, Retinal detachment

\section{Background}

Symptomatic floater is the common disease of the ophthalmological clinics. Because it may interfere with the patients' quality of vision, many patients are eager to remove their floaters. Webb [1] reported that floaters create anxiety in $76 \%$ of patients and significantly decrease the quality of life in $33 \%$ of them. In a study by Wagle et al. [2] revealed that patients with symptomatic floaters would rather sacrifice 1.1 year for every 10 years of their remaining life in order to eliminate the discomfort caused by their floaters. Currently, the main treatment methods for

\footnotetext{
*Correspondence: xiuduoliu@163.com

Yangpu district shidong hospital, Shanghai, China
}

symptomatic floaters are ND:YAG laser vitreolysis and vitrectomy. Compared with vitrectomy, Nd:YAG laser vitreolysis is much more simple, safe and economical. Complication of Nd:YAG laser vitreolysis have been reported such as cataract and glaucoma [3, 4]. In this case we reported a patient with PCO and VF who developed severe rhementogenous retinal detachment 7 days after ND:YAG laser capsulotomy and vitreolysis.

\section{Case presentation}

A 58-year-old myopic woman visited our clinic, complaining of blurred vision and symptomatic floaters in her left eye for 3 months. Ophthalmologic

(c) The Author(s). 2020 Open Access This article is licensed under a Creative Commons Attribution 4.0 International License, which permits use, sharing, adaptation, distribution and reproduction in any medium or format, as long as you give appropriate credit to the original author(s) and the source, provide a link to the Creative Commons licence, and indicate if changes were made. The images or other third party material in this article are included in the article's Creative Commons licence, unless indicated otherwise in a credit line to the material. If material is not included in the article's Creative Commons licence and your intended use is not permitted by statutory regulation or exceeds the permitted use, you will need to obtain permission directly from the copyright holder. To view a copy of this licence, visit http://creativecommons.org/licenses/by/4.0/. The Creative Commons Public Domain Dedication waiver (http://creativecommons.org/publicdomain/zero/1.0/) applies to the data made available in this article, unless otherwise stated in a credit line to the data. 


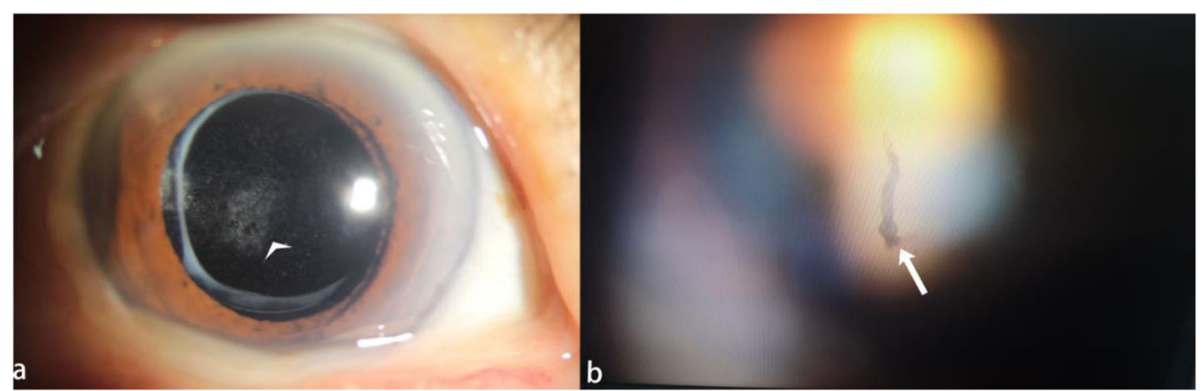

Fig. 1 a Elsching pearl like PCO (arrowhead). b vitreous floaters in the posterior segment of the vitreous cavity (arrow)

examination revealed significant Elsching pearl like PCO in her left eye and VF like a thick string in the posterior segment of the vitreous cavity(Fig. 1a). The BCVA of her left eye was $8 / 20$. She had no history of any systemic disease and drug intake. Two years ago she had undergone phacoempulsification and IOL implantation in her left eye, preoperatively she had -6.50DS myopia with her left eye and the axial length of her left eye was $26.81 \mathrm{~mm}$. We performed vitreous and retina examination on her left eye by slit-lamp biomicroscopy with Goldman's three mirror contact lens to rule out peripheral retinal tears and degeneration. By Goldmann threemirror lens, we clearly saw the partial posterior vitreous detachment (PVD) at posterior fundus and the VF was approximately $4-5 \mathrm{~mm}$ in front of the optic disc(Fig. 1b). The patient was eager to improve the visual acuity and remove the floaters in her left eye. At that time, we considered that the patient's residence was far away from our clinic. In order to reduce the number of visits of the patient, we decided to complete Nd:YAG laser capsulotomy and Nd:YAG laser vitreolysis in one time. After signing the informed consent, Nd:YAG capsulotomy was performed first, followed by Nd:YAG laser vitreolysis immediately. In order to decrease the symptoms of floaters after Nd:YAG capsulotomy, we used the cross incision method for Nd:YAG capsulotomy. The diameter of Nd:YAG capsulotomy was about $6 \mathrm{~mm}$ (Fig. 2a), the power was set from 1.6 to $3.0 \mathrm{~mJ}$, and the total power was $34 \mathrm{~mJ}$. Then we swithed the offset to the anterior to avoid the damage of the retina and optic disc behind the VF. We used the professional vitreous laser lens (the type: KARICKHOFF25mm OFF-AXIS) for vitreolysis. During the vitreolysis the energy ranged from $3.0-4.5 \mathrm{~mJ}$ for a value that fully vaporized the $\mathrm{VF}$ (Fig. 2b) and the total power of vitreolysis was $130 \mathrm{~mJ}$. In the process of Nd:YAG laser vitreolysis we found the fiber around the floaters were shaking violently. The whole timing of the two laser treatment was about $15 \mathrm{~min}$. After the laser treatment, the patient immediately complained of a prominent darking and flashing sensation with her treated eye, but the patient's complaint did not catch our attention and we did not have a timely retinal examination on her. Seven days later, she came back to our clinic complaining of rapid vision loss in her left eye and dark shadows in her lower visual field. We found her BCVA of the left eye was down to finger count at $2 \mathrm{ft}$. We found retinal detachment (RD) at the upper and nasal retina and involved the macular fovea, and two large holes in the upper retina about 4DD in diameter (Fig. 3). She immediately underwent a vitrectomy, retinal reattchment and silicone oil tamponade surgery for her left eye. Six

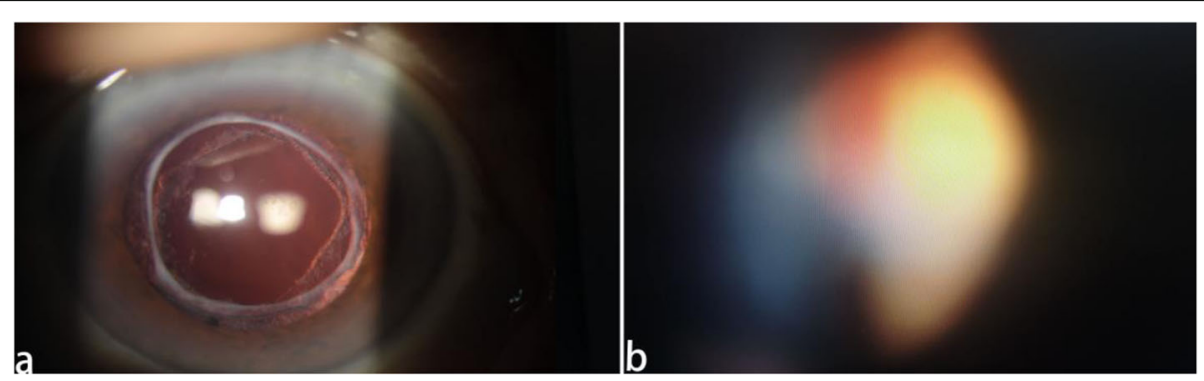

Fig. $\mathbf{2}$ a cleared posterior capsular opacity by Nd:YAG laser capsulotomy. $\mathbf{b}$ cleared vitreous floaters in the posterior segment of the vitreous cavity by Nd:YAG laser vitreolysis 


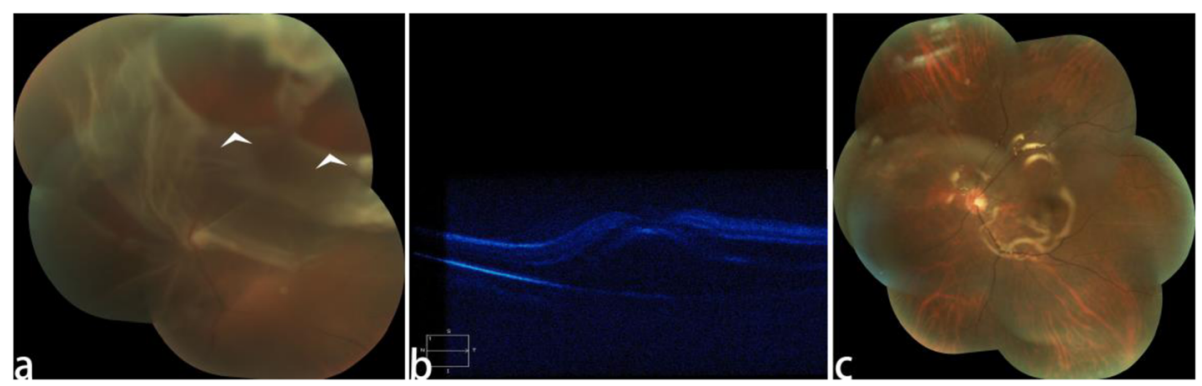

Fig. 3 the retina 7 days after Nd:YAG laser treatment (a) color fundus photograph of the left eye demonstrating the retina of upper and nasal part detachment with two large holes in the detached upper retina. $\mathbf{b}$ the optical coherence tomography show the retinal detachment involved the macular fovea. c postoperative color fundus photograph of vitrectomy, retinal reattchment and silicone oil tamponade surgery

months later silcone oil removal was arranged on her, and the BCVA in her left eye gradually improved to $10 / 20$ and maintained during a 1-year follow-up period.

\section{Discussion and conclusion}

In this case, the patient was treated with Nd:YAG laser capsulotomy and vireolysis therapy for PCO and VF in one procedure. Powell et al. [5] reported that the incidence of $\mathrm{RD}$ following Nd:YAG laser capsulotomy was $0.82 \%$, with a mean time of 13.5 months between capsulotomy and RD. A study by Wesolosky et al. [6] reported the cumulative risk of $\mathrm{RD}$ at 3, 6, 9, and 12 months after Nd:YAG laser capsulotomy was $0.6,0.96,1.19$ and $1.39 \%$, and the rates of RD varied significantly between age categories. In a study by Ranta $\mathrm{P}$ et al. [7] reported that by 5 years, the overall cumulative of proportion of RD in the 341 patients was $2.0 \%$, and the axial lenth had strongest association with RD after Nd:YAG laser capsulotomy. The axial lenth of our case was 26.81 $\mathrm{mm}$, but RD occurred as soon as 7 days after $\mathrm{Nd}$ : YAG laser capsulotomy has been rarely reported. A recent review [8] reported that Nd:YAG capsulotomy is not associated with RD, thus, it is more likely that RD developed following Nd:YAG vitreolysis rather than posterior capsulotomy. Moreover, the total energy delivered after capsulotomy was $34 \mathrm{~mJ}$, while $130 \mathrm{~mJ}$ for vitreolysis. There was no abnormality during Nd:YAG capsulotomy. However, during Nd: YAG vitreolysis, the fiber cables in the posterior segment of the vitreous were found to shake violently, this may be related to higher energy. After vitreolysis the patient immediately complained of a flash sensation. One possible explanation is that due to the 3 DD separation of floater from optic disc, the laser induced rapid completion of PVD and hence the horseshoe tear and the further RD forms. The photodisruption effect of the Nd:YAG laser seems also affects the vitreous fibers around the VF, which could cause traction to the peripheral retina then the retinal tear forms and the higher energy of vitreolysis maybe the another reason of acute $\mathrm{RD}$. There have been few studies reporting the complications following treatment with Nd:YAG vitreolysis. Cowan et al. [3] reported two cases of open angle glaucoma 7 days and 8 months after YAG laser vitreolysis with $>40 \mathrm{mmHg}$ of interocular pressure. In addition, some studies reported cataracts [4, 9]; posterior capsule defects requiring cataract surgery; retinal tear; retinal detachment [10]; retinal hemorrhages; scotomas; increased number of floaters [11]. Acute RD as severe as this case has not been reported. The laser energy should be as low as possible and it must be focused on the PCO and vitreous floaters as precisely as possible to reduce interference with retina. It is suggested that $\mathrm{Nd}$ :YAG capsulotomy maybe performed first on $\mathrm{PCO}$ and then Nd:YAG vitreolysis maybe performed after a safe interval and a thorough retinal examination. It should be alert to the possibility of RD when patients complain of prominent darking and flashing sensation flash sensation after Nd: YAG vitreolysis or capsulotomy. After this case, we did not have any $\mathrm{RD}$ complications with $\mathrm{Nd}$ : YAG laser therapy in similar patients.

\section{Abbreviations}

PCO: Posterior capsule opacification;"V VF: Vitreous floaters;

Nd:YAG: Neodymium-doped yttrium aluminum; BCVA: Best corrected visual acuity; Nd:YAG: Neodyminum-doped yttrium aluminum garnet; RD: Retinal detachment; PVD: Posterior vitreous detachment

\section{Acknowledgements \\ Not Applicable.}

\section{Authors' contributions}

XDL designed the study and was major contributors in writing the manuscript. JZ and QW helped to draft the manuscript. All authors read and approved the final manuscript.

Funding

No fundings was obtained for this study. 


\section{Availability of data and materials}

The datasets used and analysed during the current study are available from the corresponding author on reasonable request.

\section{Ethics approval and consent to participate}

This case report was approved by the ethics committee of shidong hospital, yangpu district, Shanghai. The ethical approval number is LL-LW-2019-01.

\section{Consent for publication}

The authors declare that the written consent to publish this case report was obtained from the all study participants and the patient gave written consent to the authors for her personal or clinical details to be published in this study.

\section{Competing interests}

The authors declare that they have no competing interests.

Received: 21 September 2019 Accepted: 13 April 2020

Published online: 19 April 2020

\section{References}

1. Webb BF, Webb JR, Schroeder MC, North CS. Prevalence of vitreous floaters in a community sample of smartphone users. Int J Ophthalmol. 2013;6(3): 402-5.

2. Wagle AM, Lim WY, Yap TP, Neelam K, Au Eong KG. Utility values associated with vitreous floaters. Am J Ophthalmol. 2011:152(1):60-5.

3. Cowan LA, Khine KT, Chopra V, Fazio DT, Francis BA. Refractory open-angle glaucoma after neodymium-yttrium-aluminum-garnet laser lysis of vitreous floaters. Am J Ophthalmol. 2015 Jan;159(1):138-43.

4. Huang KH, Weng TH, Chen YJ, Chang YH. latrogenic posterior Lens capsule rupture and subsequent complications due to Nd:YAG laser Vitreolysis for vitreous floaters: a case report. Ophthalmic Surg Lasers Imaging Retina. 2018:49(11):e214-7.

5. Powell SK, Olson RJ. Incidence of retinal detachment after cataract surgery and neodymium: YAG laser capsulotomy. J Cataract Refract Surg. 1995;21(2): $132-5$.

6. Wesolosky JD, Tennant M, Rudnisky CJ. Rate of retinal tear and detachment after neodymium: YAG capsulotomy. J Cataract Refract Surg. 2017;43(7):923-8.

7. Ranta P, Tommila P, Kivelä T. Retinal breaks and detachment after neodymium: YAG laser posterior capsulotomy: five-year incidence in a prospective cohort. J Cataract Refract Surg. 2004;30(1):58-66.

8. Grzybowski A, Kanclerz P. Does Nd:YAG Capsulotomy increase the risk of retinal detachment? Asia Pac J Ophthalmol, 2018;7(5):339-44.

9. Menapace R. Posterior capsule disruption with cataract formation caused by neodymium: YAG laser vitreolysis: may consultation \#1. J Cataract Refract Surg. 2018:44(5):666.

10. Benhamou N, Glacet-Bernard A, Le Mer Y, Quentel G, Perrenoud F, Coscas G, Soubrane G. Retinal detachment following YAG laser section of vitreous strands. Apropos of 3 cases. J Fr Ophtalmol. 1998;21(7):495-500.

11. Hahn P, Schneider EW, Tabandeh H, Wong RW. Emerson GG; American Society of Retina Specialists Research and Safety in therapeutics (ASRS ReST) committee. Reported complications following laser Vitreolysis. JAMA Ophthalmol. 2017;135(9):973-6.

\section{Publisher's Note}

Springer Nature remains neutral with regard to jurisdictional claims in published maps and institutional affiliations. 